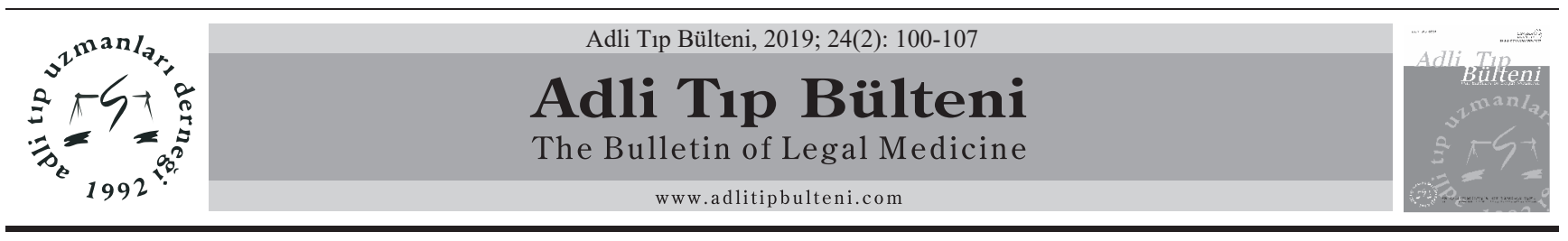

\title{
ARAŞTIRMA / RESEARCH ARTICLE \\ Profesyonel Araç Sürücülerinde Sürücü Davranışları ve Becerileri ile Alkol, Madde ve İlaç Kullanımının Değerlendirilmesi
}

\section{The Evaluation of Driver Behaviors and Skills Relation with Consumption of Alcohol, Drug Abuse and Medicine in Professional Drivers}

\author{
Alev Aktaş, Rukiye Döğer, Serap Annette Akgür*
}

\section{$\ddot{O}_{z}$}

Amaç: Sürücü davranışları ve sürücülük becerileri, trafikte kaza riskini oluşturan ana unsurlar arasında yer almaktadır. Alkol ve madde etkisi altında araç kullanma davranış1; ölümlere, maddi hasarlara ve yaralanmalara neden olan önemli bir trafik sorunudur. Bu çalışmada; profesyonel araç sürücülerinde alkol, madde ve ilaç kullanımı sıklığının araştırılarak, bu maddeler ile sürücü davranış ve becerileri arasındaki ilişkinin değerlendirilmesi amaçlanmıştır.

Gereç ve Yöntem: Çalışma İzmir ilinin 4 farklı ilçesinde çalışan 90 profesyonel araç sürücüsü ile gerçekleştirilmiştir. Sürücülere sosyo-demografik ve madde kullanımına ilişkin soruların yer aldığı anket formu, Fagerström Nikotin Bağımlılık Testi (FNBT), CAGE Alkol Tarama Testi, Sürücü Davranışları Ölçeği (SDÖ) ve Sürücülük Becerisi Ölçeği (SBÖ) uygulanmıştır. Veriler istatiksel olarak SPSS 18.0 programı ile analiz edilmiştir ( $\mathrm{p}<0,05$ anlamlılık düzeyi).

Bulgular: Sürücüler 20-67 yaşları arasında olup yaş ortalaması $42,9 \pm 12,7^{\prime}$ dir. Sürücülerin $\% 46,7$ 'si 20 yıldan fazla süredir profesyonel araç sürücüsüdür. Sürücülerin çoğunluğunda sigara $(\% 57,8)$ ve alkol $(\% 63,3)$ kullanımı vardır. Sürücülerin $\% 55,6$ 's trafikte dikkatini arttırmak ve/veya uyanık kalmak amacıyla yaşam boyu en az bir kez ağrı kesici, \%12,2'si sakinleştirici ilaç, \%1,1'i steroid, \%20'si esrar, \%3,3'ü amfetamin tipi stimülanlar (ATS), \%2,2'si sentetik esrar kullandığını belirtmiştir. Alkol ve esrar kullanımı ile hatalar, kural ihlalleri ve güvenli araç kullanma becerisi puan ortalamaları arasında anlamlı ilișki bulunmuștur.

Sonuç: Alkol, madde ve ilaç etkisi altında araç kullanma davranışının psikolojik, psikiyatrik ve adli toksikolojik bakış açısıyla çok yönlü olarak ele alınması uygulamada fayda sağlayacaktır. Çalışmamızın sonuçları ile işyeri ve trafik ortamında adli kanıt sunan madde testlerinin önemli olduğu ve aktif olarak uygulanması gerektiği görülmüștür.

Anahtar Kelimeler: Alkol; Madde Kullanımı; Trafik; Sürücü Davranışları; Sürücülük Becerileri.

\section{Abstract}

Objective: Driver behavior and skills are among the main factors that constitute the risk of accidents in traffic. Driving behavior under the influence of alcohol and drug abuse is an important traffic problem that causes deaths, pecuniary damage and injuries. The aim of the study was to investigate the frequency of alcohol, drug abuse and medicine use in professional drivers and to evaluate the relationship between these substances and driver behavior and skills.

Materials and Methods: The study was performed with 90 professional drivers working in 4 different town of İzmir. questionnaire form, Fagerström Test for Nicotine Dependence (FTND), CAGE Alcohol Screening Test, Driver Behavior Scale (DBS) and Driving Skills Scale (DSS) were applied to drivers. The data were analyzed statistically with SPSS 18.0 ( $\mathrm{p}<0.05$ significance level).

Results: Drivers were between the ages of 20-67 and the average age was 42,9 $\pm 12,7$ years. $46,7 \%$ of them have been professional drivers for more than 20 years. The majority of drivers used cigarettes $(57,8 \%)$ and alcohol $(63,3 \%)$. The reported substances and drugs use percentage from drivers were $55,6 \%$ painkillers to increase their attention and/or alertness in traffic, $12,2 \%$ tranquilizers, $1,1 \%$ steroids, $20 \%$ cannabis, $3,3 \%$ amphetamine-type stimulants (ATS), $2,2 \%$ synthetic cannabis at least once through their life-time. Significant differences were found between alcohol and cannabis use and errors, rule violations and the ability to safe driving.

Conclusion: It will be useful to consider driving behavior well-rounded with psychological, psychiatric and forensic toxicological aspects. The results of our study showed that drug abuse tests providing a forensic evidence in the workplace and traffic environment are important and needed to be actively applied.

Keywords: Alcohol; Drug Abuse; Traffic; Driver Behaviors; Driver Skills.

\section{DOI: 10.17986/blm.2019250193}

Alev Aktaş: Uzm. Psk., Ege Üniversitesi Madde Bağımlılığı, Toksikoloji ve İlaç Bilimleri Enstitüsü, Madde Bağımlılı̆̆ Anabilim Dal, İzmir

Eposta: alevalevaktas@hotmail.com ORCID iD: https://orcid.org/ 0000-00030746-0889

Rukiye Döğer: Arş. Gör., Ege Üniversitesi Madde Bağımlılı̆̆ı, Toksikoloji ve İlaç Bilimleri Enstitüsü, Bağımlılık Toksikolojisi Anabilim Dalı, İzmir

Eposta: rukiye.doger@gmail.com ORCID iD: https://orcid.org/ 0000-00024012-3684

Serap Annette Akgür: Prof. Dr., Ege Üniversitesi Madde Bağımlılığı, Toksikoloji ve İlaç Bilimleri Enstitüsü, Bağımlılık Toksikolojisi Anabilim Dalı, İzmir Eposta: serap.akgur@gmail.com ORCID iD: https://orcid.org/0000-00019638-2311

Bildirimler/ Acknowledgement: Yazarlar bu makale ile ilgili herhangi bir çıkar çatış̧ası bildirmemişlerdir. Yazarlar bu makale ile ilgili herhangi bir finansal destek bildirmemişlerdir.

The authors declare that they have no conflict of interests regarding content of this article.

The Authors report no financial support regarding content of this article.

Geliş: 20.12 .2018

Düzeltme: 15.01 .2018

Kabul: 29.01.2019

p-ISSN: $1300-865 X$

e-ISSN: 2149-4533 


\section{Giriş}

Trafik kazaları, sağlık boyutu yanında toplum güvenliği üzerine olan yaygın etkileri nedeniyle üzerinde durulması gereken önemli bir sorundur. Dünya Sağlık Örgütü'nün (DSÖ) raporuna göre; dünya çapında, her yıl karayolu trafik kazalarında ölenlerin sayısı yaklaşık 1,2 milyon, yaralananların sayısı 50 milyon olarak tahmin edilirken, trafik kazalarının 2020 yılında global hastalık yükünün önde gelen 10 nedeni içerisinde 3. s1rada olacağı öngörülmektedir (1). Sürücü davranışları ve sürücülük becerileri trafikte kaza riskini oluşturan ana unsurlar arasında yer almaktadır (2). Sürücü davranışı; sürücünün araç kullanımında sergilediği hız yapma ya da trafik kurallarını ihmal etme gibi doğrudan kaza riskiyle ilgili davranışları ve trafik güvenliğine ilişkin tutumlarını tanımlamaktadır. Sürücülük becerileri ise; daha çok sürücünün araç kullanımında ne oranda yetkin ve deneyimli olduğunu ve mesafe tahmini, çevresel algı gibi fizyolojik özelliklerin düzeyini belirtmektedir (3). Alkol, madde ve ilaç etkisi altında araç kullanma davranışı olumsuz sürücü davranışları arasında yer almaktadır. Psikoaktif etkileri olan bu maddelerin kullanımı, sürüş becerileri açısından önemli olan birçok özelliği etkilemekte, yol güvenliğini tehlikeye sokmakta ve ölümlü ya da yaralanmalı trafik kazasına sebep olmaktadır.

Kan alkol düzeyinin 0,5 promil $(50 \mathrm{mg} / \mathrm{dL})$ ve üzerinde olması durumunda, kişilerin bilişsel fonksiyonları olumsuz etkilenmekte olup bu değerin üzerindeki her artış bilişsel, motor ve algısal fonksiyonlar üzerinde bozucu etki ortaya çıkarmaktadır (4,5). Kan alkol düzeyinin 0,50 ile 0,79 promil arasinda olması ile kaza riskinde 7 ile 21 kat arasında bir artışın söz konusu olduğu bildirilmiştir (6). Alkol kullanımında olduğu gibi yasal/yasadışı madde kullanımının da sürücülerde kazaya karışmada etkili bir faktör olduğu ve alkollü araç kullanmaktan daha tehlikeli durum olarak değerlendirildiğini belirten çalışmalar mevcuttur $(7,8)$. Yapılan araştırmalarda, alkol dışında suistimal edilebilme ihtimali yüksek olan ve kullanımı gittikçe yaygınlaşan psikoaktif yasadışı maddelerden esrar ve amfetaminin, araç kazalarında artışa sebep olduğu ve sürücülük becerilerini olumsuz etkilediği gösterilmiştir (9-12). Avrupa Uyuşturucu ve Uyuşturucu Bağımlılığ1 İzleme Merkezi (EMCDDA)'nin yürüttüğü projenin bulgularına göre, çoklu madde kullanımı sürücü becerilerini etkileyerek trafik kazası riskini 5-30 kat artırırken, alkolle maddelerin birlikte kullanımı kaza riskini 20-200 kat artırmaktadır (13). Yapılan bir çalışmada, sürücülerin \%54,8'inde kaza yaptığı sırada alkol ya da madde kullanımının olduğu bildirilmiştir (14). 2014 yılında İspanya'da sürücülerle yapılan bir araştırmada, madde etkisi altında araç kullanımının \%1,9 oranında olduğu rapor edilmiştir
(15). Avustralya'da amatör ve profesyonellerden oluşan 2500 yaralı sürücünün \%8,6'sının kan örneklerinde alkol, $\%$ 7,1' inde esrar, \%3'ünde alkol ve esrar saptanmıştır (16). 2011 yılında Drummer ve arkadaşlarının Avustralya'da 1714 yaralı sürücü ile yaptıkları bir araştırmada kan örneklerinden elde edilen analiz sonuçlarına göre, sürücülerin \%29'unda alkol ve \%35'inde madde saptanmıştır. Saptanan maddelerin içerisinde \%9,8 esrar (THC), \%0,4 opioidler, \%9,2 oranında antidepresanlar, \%8,9 benzodiazepinler, \%3,1 metamfetamin, \%1,7 antipsikotikler ve $\% 0,8$ oranında ekstazi (MDMA) bulunmaktadır. Sürücülerde maddenin yanında alkolün birlikte bulunma oranı \%12 olarak bildirilmiştir (7). Başka bir çalışmada, hafta sonu gece araç kullanan sürücülerin \%14,4’ünde yasadışı madde kullanımı olduğu yapılan tükürük analizi sonucunda tespit edilmiş ve $\% 8,5$ oranında en yaygın olarak kullanılan maddenin esrar olduğu saptanmıştır (17).

Ülkemizde araç sürücülerinin trafikte izin verilen s1nırların üzerinde alkol ve madde kullanımının önlenmesini amaçlayan yasal düzenlemeler mevcuttur. Ayrıca, 5237 Sayılı Türk Ceza Kanunun 179. Maddesi uyarınca alkol veya uyuşturucu madde etkisiyle ya da başka bir nedenle emniyetli bir şekilde araç sevk ve idare edemeyecek hâlde olmasına rağmen araç kullanan kişinin cezalandırılacağ hükmolunmuştur. 2918 sayılı Karayolları Trafik Kanunun 48. Maddesi uyarınca da; uyuşturucu veya keyif verici maddeleri almış olanlar ile alkollü içki almış olması nedeniyle güvenli sürme yeteneklerini kaybetmiş kişilerin karayolunda araç sürmeleri yasaktır. Kanuna göre; 0.50 promilin üzerinde alkollü olarak araç kullandığı tespit edilen sürücüler hakkında idari para cezası verilmekte ve sürücü belgesi altı ay süreyle geri alınmaktadır. Hususi otomobil dışındaki araçları alkollü olarak kullanan sürücüler bakımından promil alt sınırı ise 0.21 olarak uygulanmaktadır. $\mathrm{Bu}$ düzenlemelere karşın yapılan çalışmalar, ülkemizde araç sürücülerinde alkol ve madde kullanımı olduğu gerçeğini ortaya koymaktadır. Örneğin, uzun yol araç sürücülerinde sözlü beyana dayalı olarak yapılan bir çalışmada, sürücülerin \%28,9'unun esrar kullandığı bildirilmiştir (18). Bir Acil Tıp Anabilim Dalına trafik kazası sebebiyle başvuran sürücülerin \%40,2'sinin kan analizinde alkol tespit edilmiş ve alkollü sürücülerin $\% 66,7$ 'sinin alkol düzeyinin yasal sınırın (0,5 promil) üstünde olduğu bildirilmiştir (19). 2011 yılında yapılan bir araştırmada 348 trafik kazası olgusunun \%37,1'inin kanında alkol saptanmış ve ölümlü trafik kazalarının \%55,4'ünde alkol pozitif bulunmuştur (20). 2010 ile 2011 yılları arasında madde kullanımı açısından şüpheli olduğu tespit edilen ve kazaya karışan 91 sürücünün \%44'ünün kanında alkol ve \%15,4'ünün kanında psikoaktif madde saptanmıştır (21). 2015 yılında yapılan bir araştırmanın sonuçlarına göre; araç kullanan 
ve psikiyatrik bir tanısı olan hastaların \%32,4'ü alkollü araç kullandıklarını, \%7,4'ü alkol veya madde kullanımına bağlı trafik kazası yaptığını bildirmiştir (22).

Yapılan çalışmaların sonuçlarından da görüldüğü üzere, alkol ve madde etkisi altında araç kullanma davranış1 ölümlere, maddi hasarlara ve yaralanmalara yol açan önemli bir trafik güvenliği sorunudur. Trafik kazalarında alkol ve madde kullanımı ile ilgili sürücü davranışları ve becerileri konusunda ülkemizdeki çalışmalar sınırlıdır. Bu çalışmada; profesyonel araç sürücülerinde alkol, madde, ilaç kullanım sıklığının araştırılması ve bu maddeler ile sürücü davranış becerileri arasındaki ilişkinin değerlendirilmesi amaçlanmıştır.

\section{Gereç ve Yöntem}

Çalışma; 20-67 yaş aralığında, 30 servis, 30 taksi ve 30 minibüs sürücüsü olmak üzere toplamda 90 profesyonel erkek araç sürücüsü ile gerçekleştirilmiştir. Çalışma için Ege Üniversitesi Tıp Fakültesi Klinik Araştırmalar Etik Kurulu'ndan onay alınmıştır (02.05.2012 tarihli ve 12-5/29 nolu karar). 09.04.2012 ile 02.09.2013 tarihleri arasında İzmir ilinin 4 farklı ilçesinde çalışan sürücülerin çalışma alanlarına gidilerek, gönüllü olarak araştırmaya katılmayı kabul edenlerle bekleme kulübelerinde birebir görüşmeler yapılmıştır. Araştırmada, araştırmacı tarafından hazırlanan sosyo-demografik soruların ve madde kullanımına ilişkin soruların yer aldığı anket formu, 2004 yılında Uysal ve arkadaşları tarafından geçerlilik ve güvenirlik çalışması yapılan ve nikotinin fiziksel bağımlılığı yönünden riski değerlendirmek, düzeyini ölçmek amacıyla geliştirilen Fagerström Nikotin Bağımlılık Testi (FNBT)(23), alkolizm tanısı için güvenirliği tespit edilen ve içki içmeyle ilişkili kontrol kaybını, ruhsal sonuçları, kişilerarası sorunları ve fizyolojik bağımlılığı sorgulayan CAGE (Cutdown, Annoyed, Guilty, Eyeopener) Alkol Tarama Testi (24) kullanılmıştır. Ayrıca geçerlilik ve güvenirlik çalışmalar1 ülkemizde 2004 yılında Lajunen ve Özkan tarafından gerçekleştirilen, sürücülerin araç kullanırken karşılaşılan muhtemel durumları kendileri için ne sıklıkta yaşadıklarını değerlendirmek amacıyla Sürücü Davranışları Ölçeği (SDÖ) ve sürücülük becerilerini sürücü beyanı temelinde ölçmek amacıyla Sürücülük Becerisi Ölçeği (SBÖ) kullanılmıştır (25). Veriler, SPSS 18,0 paket programı kullanılarak analiz edilmiş ve istatistiksel anlamlılık için $\mathrm{p}<0,05$ kabul edilmiştir. Analizlerde Ki-Kare Test, Mann-Whitney U Test ve Kruskal Wallis H Test kullanılmıştır.

\section{Bulgular}

Anket ve ölçeklere verilen cevaplar analiz edildiğinde; sürücülerin yaş ortalaması $42,9 \pm 12,7$ 'dir. Sürü- cülerin \%38,9'u ilkokul, \%16,7'si ortaokul, \%38,9'u lise ve $\% 5,5$ 'i üniversite mezunudur. \%15,6's1 1-5 yı1, \%14,4'ü 6-10 y1l, \%12,2'si 11-15 y1l, \%11,1'i 16-20 y1l ve \%46,7'si 20 yıldan fazla süredir ticari araç sürücülüğü yapmaktadır. \%73,3'ü hayatı boyunca en az bir kez aktif kaza (sürücünün bir başka nesneye çarpması) ve \%83,3'ü pasif kaza (sürücüye bir başka sürücü tarafindan çarpılması) yapmıştır. \%35,6'sı da son bir yılda hemen her gün trafikte ucuz atlatma (potansiyel kaza) yaşamıştır.

Sürücülerin trafik cezası alma nedenleri çeşitlilik göstermektedir (Tablo 1). Buna göre; katılımcıların \%11,1'i yaşam boyu en az bir kez alkollü araç kullanma nedeniyle trafik cezası aldığını belirtmiştir, ancak madde etkisi altındayken araç kullanma nedeniyle trafik cezası alan sürücüye rastlanmamıştır.

Tablo 1. Sürücülerin Aldığı Trafik Cezalarının Nedenleri.

\begin{tabular}{|l|c|c|}
\hline Ceza Nedeni & (n) & (\%) \\
\hline Aşırı hız & 44 & 48,9 \\
\hline Kaza & 11 & 12,2 \\
\hline Alkol & 10 & 11,1 \\
\hline Emniyet kemeri & 19 & 21,1 \\
\hline Eksik evrak & 37 & 41,1 \\
\hline Madde kullanımı & 0 & 0 \\
\hline Cep telefonu kullanma & 12 & 13,3 \\
\hline Kırmızı 1şı ihlali & 24 & 26,7 \\
\hline Hatalı sollama & 5 & 5,6 \\
\hline Yanlış park etme & 38 & 42,2 \\
\hline Fazla yolcu taşıma & 29 & 32,2 \\
\hline
\end{tabular}

Sürücülerin \%57,8'i halen sigara kullanımının olduğunu bildirmiştir ve FNBT puan ortalaması 4,62 olarak hesaplanmıştır (Tablo 2).

Tablo 2. Sürücülerin Sigara Kullanımına İlişkin Bilgiler.

\begin{tabular}{|l|c|c|}
\hline Sigara & (n) & (\%) \\
\hline Halen kullanıyor & 52 & 57,8 \\
\hline Bırakmış & 24 & 26,7 \\
\hline Hiç kullanmamış & 14 & 15,6 \\
\hline Toplam & $\mathbf{9 0}$ & $\mathbf{1 0 0}$ \\
\hline FNBT \\
\hline Çok az (0-2 puan) & 17 & 32,7 \\
\hline Az (3-4 puan) & 10 & 19,2 \\
\hline Orta (5 puan) & 6 & 11,5 \\
\hline Yüksek (6-7 puan) & 9 & 17,3 \\
\hline Çok yüksek (8-10 puan) & 10 & 19,2 \\
\hline Toplam & $\mathbf{5 2}$ & $\mathbf{1 0 0}$ \\
\hline
\end{tabular}


Tablo 3 'te yer alan sürücülerin alkol kullanımına ilişkin bilgilere bakıldığında; \%63,3 gibi büyük oranda alkol kullanımını sürdürdüklerini beyan etmişlerdir. CAGE tarama testi sonuçlarına göre; halen alkol kullanan katılımcıların \%24,6'sı 2 veya daha fazla evet cevabı vermiştir ve bu katılımcılar riskli alkol kullanan grubu oluşturmaktadir.

Tablo 3. Sürücülerin Alkol Kullanımına İlişkin Bilgiler.

\begin{tabular}{|l|c|c|}
\hline Alkol & (n) & (\%) \\
\hline Halen kullanıyor & 57 & 63,3 \\
\hline Bırakmış & 24 & 26,7 \\
\hline Hiç kullanmamış & 9 & 10 \\
\hline Toplam & $\mathbf{9 0}$ & $\mathbf{1 0 0}$ \\
\hline Son 12 ay alkol kullanımı & \multicolumn{2}{|l|}{} \\
\hline Sadece 1 kez & 4 & 7 \\
\hline Sadece birkaç kez & 9 & 15,8 \\
\hline Ayda 1-2 kez & 11 & 19,3 \\
\hline Ayda 3-4 kez & 3 & 5,3 \\
\hline Haftada 1-2 kez & 16 & 28,1 \\
\hline Haftada 3-4 kez & 7 & 12,3 \\
\hline Hemen her gün & 7 & 12,3 \\
\hline Toplam & $\mathbf{5 7}$ & $\mathbf{1 0 0}$ \\
\hline Son 30 gün alkol kullanımı & \multicolumn{2}{|l|}{} \\
\hline Hiç & 8 & 14 \\
\hline 1 gün & 9 & 15,8 \\
\hline 2 gün & 4 & 7 \\
\hline 3-5 gün & 13 & 22,8 \\
\hline 6-10 gün & 9 & 15,8 \\
\hline 11-20 gün & 5 & 8,8 \\
\hline 21-28 gün & $\mathbf{5 7}$ & 8,8 \\
\hline Her gün & $\mathbf{1 0 0}$ \\
\hline Toplam & \multicolumn{2}{|l|}{} \\
\hline
\end{tabular}

Sürücülerin madde kullanımı ile ilgili olarak beyanları değerlendirildiğinde ( $n=90)$ en yaygın kullanılan maddenin esrar olduğu saptanmıştır (Tablo 4). Esrar kullanımı olan 18 sürücünün son 12 ay içinde $\% 11,1$ 'i $(n=2)$ sadece birkaç kez, \%5,6'sı (n=1) ayda 1 kez, \%5,6'sı (n=1) haftada 1 kez esrar kullandığını ve \%77,8'i $(n=14)$ ise esrar kullanımı olmadığını belirtmiştir. Esrar kullanımı olan 1 sürücü son 30 gün içinde haftada 3-4 kez esrar kullanımının olduğunu belirtmiştir.

Sürücülerin \% 42,2'si ( $n=38$ ) yaşam boyu en az bir kez alkol dışında tıbbi amaç olmaksızın psikoaktif madde kullandığını belirtmiştir. Madde kullanımı olan 38 sürücünün \%28,9'u yaşam boyu çoklu yasal ve yasadışı madde kullanımı olduğunu beyan etmiştir (Tablo 5). Kulla- nım nedenlerine bakıldığında; \%47,4'ü ilk kullanımlarını rahatlamak ve keyif almak, \%36,8'i arkadaşlarına eşlik etmek, \%15,8'i merak, \%5,3'ü sakinleşmek, \%2,6's1 uyuyabilmek, \%2,6'sı sorunlarından uzaklaşmak vb. olarak bildirmişlerdir.

Tablo 4. Sürücülerin Madde Kullanımına İlişkin Bilgiler.

\begin{tabular}{|l|c|c|c|c|}
\hline \multirow{2}{*}{ Maddenin ismi } & \multicolumn{2}{|c|}{ Evet } & Hayır & \\
\cline { 2 - 5 } & (n) & $\mathbf{( \% )}$ & (n) & $\mathbf{( \% )}$ \\
\hline Esrar & 18 & 20,0 & 72 & 80,0 \\
\hline Kodeinli ilaç & 16 & 17,8 & 74 & 82,2 \\
\hline Yatıştırıcı, sedatif ilaç & 11 & 12,2 & 79 & 87,8 \\
\hline $\begin{array}{l}\text { Amfetamin tipi stimülanlar } \\
\text { (ATS) }\end{array}$ & 3 & 3,3 & 87 & 96,7 \\
\hline Sentetik esrar & 2 & 2,2 & 88 & 97,8 \\
\hline Steroid içeren ilaç & 1 & 1,1 & 89 & 98,9 \\
\hline
\end{tabular}

Tablo 5. Sürücülerin Yaşam Boyu Çoklu Madde Kullanımına İlişkin Bilgiler.

\begin{tabular}{|l|c|c|}
\hline Yasal/Yasadışı Madde & $\mathbf{n}$ & $\mathbf{\%}$ \\
\hline Esrar + sentetik esrar + ATS & 1 & 2,6 \\
\hline Esrar + sentetik esrar + kodeinli ilaç & 1 & 2,6 \\
\hline Esrar + kodeinli ilaç & 5 & 13,2 \\
\hline Esrar + steroid içeren ilaç & 1 & 2,6 \\
\hline Esrar + yatıştırıcı, sedatif ilaç & 2 & 5,3 \\
\hline Yatıştırıcı, sedatif ilaç +kodeinli ilaç & 1 & 2,6 \\
\hline Çoklu madde yok & 27 & 71,1 \\
\hline Toplam & $\mathbf{3 8}$ & $\mathbf{1 0 0}$ \\
\hline
\end{tabular}

Sürücülerin yaşam boyu alkol kullanımı ile madde kullanımı arasındaki ilişkiyi test etmek amacıyla yapılan analiz sonucuna göre; alkol kullanımı olan sürücülerin anlamlı çoğunluğu $(\% 76,3)$ en az bir kez madde kullanan grubu oluşturmaktadır $\left(\chi^{2}(2)=6,269, p<0,05\right)$. Ayrıca, yaşam boyu alkol kullanımı ile esrar kullanımı arasında da istatistiksel olarak anlamlı farklılaşma bulunmuştur $\left(\chi^{2}(2)=13,026, p<0,05\right)$. Buna göre esrar kullanımı olan sürücülerin tamamı alkol kullanmaktadır. Burada anket uygulamasına katılan sürücülerin sosyal arzulanırlık nedeniyle kaza geçmişleri ve alkol-madde kullanımı konusundaki beyanlarının yanlı olabileceği ihtimali de göz önünde bulundurulmalıdır.

Sürücü grubu ile alkol ve madde kullanımı arasında yapılan analiz sonuçlarına göre; minibüs sürücülerinde taksi ve servis sürücülerine kıyasla alkol kullanımı $\left(\boldsymbol{\chi}^{2}(4)=20,390 ; \mathrm{p}<0,05\right)$ ve madde kullanımı $\left(\chi^{2}(2)=12,115 ; p<0,05\right)$ daha yüksek oranda bulunmuştur. 
Sürücülerin alkollü araç kullanma nedeniyle trafik cezası alması ile esrar kullanım durumu arasında istatistiksel olarak anlamlı farklılaşma bulunmuş $\left(\chi^{2}(1)=17,578\right.$; $\mathrm{p}<0,05)$ ve alkollü araç kullanma nedeniyle trafik cezası alan sürücülerin \%70'i yaşamı boyunca en az bir kez esrar kullandığını bildirmiştir.

Sürücülerin \%38,9'u trafikte alkol etkisi altındayken ticari araç ve \%57,8'i özel (kişisel) araç; esrar etkisi altındayken \%4,4’ü ticari araç ve \%11,1'i özel (kişisel) araçları en az bir kez kullandığını belirtmiştir. Sürücülerin \% 73,3'ü aktif olarak çalışırken en az bir kez alkol testine tabi tutulduğunu bildirmiştir.

Sürücülerin \%55,6’sı (n=50) son 1 yıl içinde hekim önerisi olmaksızın rahatlamak veya dikkatini arttırmak, uyanık kalmak amacıyla bir defadan fazla ağrı kesici kullandığını bildirmiștir.

Alkol kullanımı ile SDÖ ve SBÖ alt ölçekleri arasındaki ilişkiyi test etmek amacıyla yapılan Kruskall Wallis $\mathrm{H}$ Test analizleri sonucunda hatalar $\left(\chi^{2}(2)=10,738\right.$; $\mathrm{p}=0,005)$, kural ihlalleri $\left(\chi^{2}(2)=10,104 ; \mathrm{p}=0,006\right)$, araç kullanma $\left(\chi^{2}(2)=6,259 ; p=0,044\right)$ ve güvenli araç kullanma $\left(\chi^{2}(2)=8,802 ; p=0,012\right)$ becerisi alt ölçeklerinde istatistiksel olarak anlamlı farklılaşma bulunmuştur (Şekil 1). Buna göre; alkol kullananların kural ihlalleri alt ölçeği puan ortalamaları (ort. 52,02) daha yüksek, güvenli araç kullanma becerisi alt ölçeği puan ortalamaları (ort. 41,26) ise daha düşük bulunmuştur.

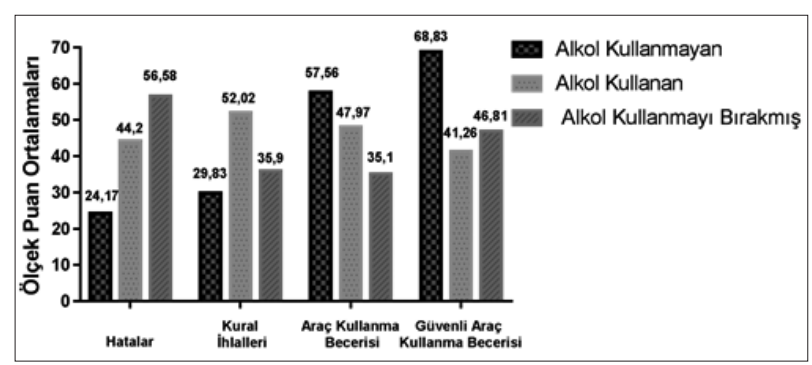

Şekil 1. Alkol Kullanımına Göre SDÖ ve SBÖ Alt Ölçekleri Puan Ortalamaları.

Esrar kullanımı ile SDÖ ve SBÖ alt ölçekleri arasındaki ilişkiyi test etmek amacıyla yapılan Mann-Whitney $\mathrm{U}$ Test analizleri sonucunda hatalar $(\mathrm{U}=453,000 \mathrm{Z}=-1,993$ $\mathrm{p}=.046)$, kural ihlalleri $(U=356,500 \mathrm{Z}=-2,952 \mathrm{p}=0,003)$, saldirgan ihlaller $(U=400,500 \quad Z=-2,513 \quad p=0,012)$ ve güvenli araç kullanma becerisi ( $U=347,500 \mathrm{Z}=-3,042$ $\mathrm{p}=0,002$ ) alt ölçeklerinde istatistiksel olarak anlamlı farklılaşma bulunmuştur (Şekil 2). Buna göre; esrar kullanımı olanların hatalar (ort. 56,33), kural ihlalleri (ort. 61,69), saldırgan ihlaller (ort. 59,25) alt ölçekleri puan ortalamaları daha yüksek, güvenli araç kullanma becerisi alt ölçeği puan ortalamaları (ort. 28,81) ise daha düşük bulunmuştur.

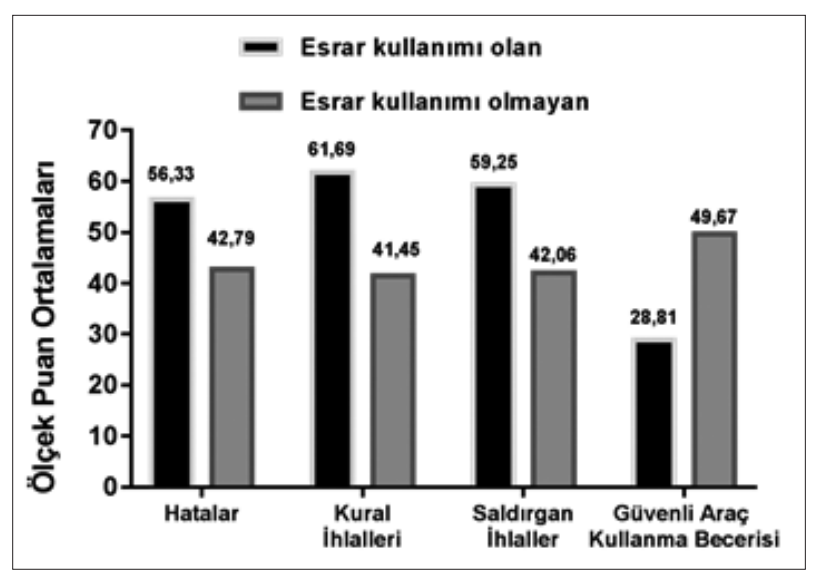

Şekil 2. Esrar Kullanımına Göre SDÖ ve SBÖ Alt Ölçekleri Puan Ortalamaları.

\section{Tartışma}

Trafik kazaları, Dünyada ve Ülkemizde önemli bir toplumsal güvenlik sorunudur ve her y1l kazalar nedeniyle binlerce kişi zarar görmektedir. Kaza istatistikleri ile trafik kazalarında en çok kusurun \%95'ten yüksek bir oranla sürücülerde olduğu belirtilmiştir (26). İzmir'in 4 farklı ilçesinde 90 profesyonel sürücü ile gerçekleştirilen çalışmamızda, sürücü davranışları ve becerileri ile alkol, madde ve ilaç kullanım yaygınlığı arasındaki ilişki değerlendirilmiştir. Çalışmamıza katılan sürücülerin $\% 57,8$ 'i sigara ve \%63,3'ü alkol kullandığını belirtmiştir. Yapılan araştırmalarda da benzer sonuçlar sunulmuştur $(3,19,27,28)$.

Çalışmamızda sürücüler ağrı kesici ilaçları $(\% 55,6)$ hekim önerisi olmadan trafikte çalışırken dikkatini arttırmak veya uyanık kalabilmek amacıyla son bir yıl içerisinde en az bir kez suistimal ettiklerini beyan etmişlerdir. Ağrı kesici ve ateş düşürücü olarak etki gösteren ilacın içeriğinde parasetamol ve kafein bulunmaktadır (29). Ülkemizde yapılan araştırmalarda profesyonel araç sürücülerinin tıbbi olarak önerilmediği halde suistimal ettikleri ilaçların başında genellikle ağrı kesicilerin ve özellikle uzun yol araç sürücülerinde içerdiği kafeinin uyarıcı etkisi nedeniyle uyanık kalmayı sağlayan gripinin yaygın olduğu görülmektedir (28,30). Sürücülerin \%42,2'si yaşam boyu en az bir kez tıbbi amaçlı kullanım harici yasadışı madde kullandığını bildirmiştir. 2009 yılında profesyonel araç sürücüleriyle yapılan bir çalışmada alkol dışı madde kullanma oranı \%28,8' dir ve bu oran ilaç dışındaki maddeleri kapsamaktadır (18). Bunun yanında literatürde sürücülerle yapılan pek çok çalışmada olduğu gibi $(17,21)$ çalışmamızda da alkol dışında en yaygın kullanımı olan madde esrardır. 
Araştırmamızda sürücülerin $\% 73,3$ 'ü trafikte çalışırken en az bir kez alkol testine tabi tutulduğunu, \%26,7'si alkol testine hiç tabi tutulmadığını ve \%11,1'i alkollü araç kullanma nedeniyle trafik cezası aldığını bildirmiştir. 16 ile 20 yıl arası uzun süredir profesyonel araç sürücüsü olarak çalışanların \%40'ının ve 20 yıldan fazla süredir çalışanların \%14,3’ünün bu zamana kadar trafikte hiç alkol testine tabi tutulmaması dikkat çekici bir veridir. Ayrıca araştırmaya katılan 7 sürücü alkollü araç kullandığı halde hiç alkol testine tabi tutulmadığını ve ceza almadığını belirtmiştir. Pek çok dünya ülkesinde caydırıcı nitelikte olduğu yönünde kabul gören trafikte alkol testi uygulaması ülkemizde rutin olarak yapılmaktadır, ancak trafikte madde testleri için henüz rutin olarak böyle bir uygulama mevcut değildir. Dünyada profesyonel araç sürücülerinde madde testi uygulaması iki şekilde yapılmaktadır. Bu uygulamalardan ilki kişilerin bağlı oldukları ilgili kurumlar kapsamında işyeri madde testi (Workplace Drug Testing, WDT) (31), ikincisi ise trafikte seyir halindeyken sürücülerde yapılan madde testidir (Driving Under The Influence of Drugs, DRUID) (32). Araştırmamızda da trafikte çalışırken alkol dışı madde testine tabi tutulduğunu beyan eden sürücüye rastlanmamıştır. $\mathrm{Bu}$ veriler, profesyonel araç sürücülerinde madde testlerinin yapılması gerekliliğini ve önemini gözler önüne sermektedir.

Alkol kullanımı olan katılımciların, kullanımı olmayanlardan daha fazla hata ve kural ihlali davranışlarında bulundukları ve daha az araç kullanma becerisi ve güvenli araç kullanma becerisine sahip oldukları saptanmıştır. Bu durum özellikle alkol kullanımının sürücü davranışları ve becerileri üzerindeki olumsuz etkisinin varlığıyla açıklanabilir. Bernosky Smith ve arkadaşları tarafından 2012 yılında yapılan araştırma sonucuna göre; sürücülerde alkol kullanımının trafikte riskli davranışları artırdığ ve özellikle alkol alımının hızlı olmasının riskli sürücü davranışı ile ilişkili olduğu bulunmuştur (33). Mesleği sürücülük olan kişilerin yaşam öykülerinde esrar kullanımının da olması trafik ortamında araç kullanma davranışı ve araç kullanma becerisi üzerinde risk faktörü olabilmektedir. Deneysel bir çalışma sonucunda yüksek doz esrar alan grubun esrar almayan plasebo grubundan daha yavaş tepkide bulunduğu, fakat bu farkın istatistiksel olarak anlamlı olmadığı bildirilmiştir (34). Madde kullanımının trafikte kazalar ve riskli sürücü davranışlarıyla ilişkili olduğunu bildiren başka yayınlar da mevcuttur $(35,36)$. Araştırmamız sonucunda da yaşam boyu en az bir kez esrar kullanımı olan sürücülerin, kullanımı olmayanlardan daha fazla hata, kural ihlali ve saldırgan ihlal davranışlarında bulundukları ve daha az güvenli araç kullanma becerisine sahip oldukları görülmüştür.
Dünya genelinde mevcut yayınlar incelendiğinde; farklı tekniklerin ve adli/analitik toksikolojik verilerinin kullanıldığı çok sayıda çalışma olup, ülkemizde ise daha çok sürücülerin sözlü beyanına göre yapılan alkol, madde ve ilaç kullanımı ile ilgili çalışmalar mevcuttur. Ancak profesyonel araç sürücüleri ile ilgili çalışmalar kısıtlı sayıdadır. Bu araştırmada da profesyonel araç sürücülerinin sözlü beyanlarından alınan bilgilerle alkol, madde ve ilaç kullanım özellikleri değerlendirilmiştir. Bu amaçla alkol, madde ve ilaç kullanımıyla ilgili sorular yarı yapılandırılmış görüşme tekniği çerçevesinde sorulmuş ve cevaplar anket formuna araştırmacı psikolog tarafindan dikkatle işaretlenmiştir. Bu kapsamda bulguların yorumlanmasında; yasadışı madde kullanımının ülkemizde suç olması ve sosyal arzulanırlık nedeniyle kişiler tarafindan gizli tutulmaya çalışılabileceği eğilimi göz önünde bulundurulmalıdır. Psikoaktif maddelerin saptanmasına yönelik çeşitli biyolojik materyallerle (saç, tükürük, idrar, kan gibi) yapılan adli toksikolojik analiz sonuçlarının bu tür çalışmalarda kullanılması yararlı olacaktır. Ek olarak, trafikte sürücülerdeki alkol testi uygulamasında olduğu gibi madde testlerinin rutin ve etkin olarak yapılmasının uyuşturucu, uyarıcı ve keyif verici psikoaktif maddelerle mücadeledeki başarıyı artıracağı düşünülmektedir. Sürücülerin madde etkisi altında olup olmadığının ve/veya madde kullanıp kullanmadığının belirlenmesi amacıyla yapılacak testlerde mutlak amaç, adli alanla ilişkisi nedeniyle, toksikolojik analizlerde en doğru sonucun alınmasıdır. Madde saptanmasına yönelik adli toksikolojik analizlerde, örneğin, uygun ön tarama test yönteminin seçilmemesi, doğrulama yapılmadan ön tarama testi sonucunda yasal işlemlerin uygulanması, örnek temin/transferinde gerekli emniyet \& gözetim zincirin sağlanamaması, ön tarama testindeki analitlerin ve eşik değerlerinin aynı/ standart olmaması gibi durumlar söz konusu olabilir. Bu koşullarda; bir maddenin kişide saptanamaması veya gerçekte bulunmayan bir maddenin tespit edilmesi gibi telafisi mümkün olmayacak durumlar gelişebilmektedir. İlgili uluslararası rapor ve rehberlere (DRUID, EWDTS) göre gerekli tedbirlerin alınmasıyla bu tür sorunların önüne geçebilmek mümkün olabilecektir.

\section{Sonuç}

Alkol, madde ve ilaç etkisi altında araç kullanma davranışı trafik güvenliğini tehlikeye sokan olumsuz sürücü davranışlarındandır. Konunun çok yönlü olarak psikoloji ve adli toksikoloji bakış açısıyla ele alınması uygulamada fayda sağlayacaktır, bu aşamada trafikte madde testleri önem taşımaktadır. Bu araştırmanın sonuçları, profesyonel araç sürücülerinin alkol, madde ve ilaç kullanımları 
açısından rutin olarak denetlenmesi ve değerlendirilmesi gerektiğini göstermektedir.

\section{Teşekkür}

Araştırmamıza vermiş oldukları desteklerden dolayı; Doç. Dr. Mehmet Koyuncu'ya, Prof. Dr. Türker Özkan'a, İzmir Otobüsçüler ve Umum Servis Araçları İşletmecileri Odası Başkanı Hasan Basri Bostancı’ya, Uzm. Psk. Fatma Dilek Şeker'e ve rahmetle andığımız Uzm. Psk. Şenay Güler Akın’a teşekkürlerimizi sunarız.

\section{Kaynaklar}

1. WHO. World report on road traffic injury prevention. 2004 [Erişim Tarihi: 19Aralık 2018].http://apps.who.int/iris/bitstream/handle/10665/42871/9241562609.pdf?sequence $=1$

2. Elander J, West R, French D. Behavioral correlates of individual differences in road-traffic crash risk: an examination method and findings. Psychological bulletin. 1993;113(2): 279-294. http://www.ncbi.nlm.nih.gov/pubmed/8451335.

3. Sümer N, Özkan T. Sürücü Davranışları, Becerileri, Bazı Kişilik Özellikleri ve Psikolojik Belirtilerin Trafik Kazalarındaki Rolleri. Türk Psikoloji Dergisi. 2002;17(50): 1-22.

4. Schweizer TA, Vogel-Sprott M, Danckert J, Roy EA, Skakum A, Broderick CE. Neuropsychological Profile of Acute Alcohol Intoxication during Ascending and Descending Blood Alcohol Concentrations. Neuropsychopharmacology. 2006;31(6): 1301-1309. DOI: https://doi.org/10.1038/ sj.npp.1300941.

5. Dry MJ, Burns NR, Nettelbeck T, Farquharson AL, White JM. Dose-Related Effects of Alcohol on Cognitive Functioning. Mendelson JE (ed.) PLoS ONE. Public Library of Science; 2012;7(11): e50977. DOI: https://doi.org/10.1371/ journal.pone.0050977.

6. Fell JC, Voas RB. The effectiveness of a 0.05 blood alcohol concentration (BAC) limit for driving in the United States. Addiction. 2014;109(6): 869-874. DOI: https://doi. org/10.1111/add.12365.

7. Drummer OH, Kourtis I, Beyer J, Tayler P, Boorman M, Gerostamoulos D. The prevalence of drugs in injured drivers. Forensic Science International. 2012;215(1-3): 14-17. DOI: https://doi.org/10.1016/j.forsciint.2011.01.040.

8. Kumar S, Bansal YS, Singh D, Medhi B. Alcohol and Drug Use in Injured Drivers - An Emergency Room Study in a Regional Tertiary Care Centre of North West India. Journal of clinical and diagnostic research : JCDR. JCDR Research \& Publications Private Limited; 2015;9(7): HC01-4. DOI: https://doi.org/10.7860/JCDR/2015/14840.6239.

9. Grotenhermen F, Leson G, Berghaus G, Drummer OH, Krüger H-P, Longo M, et al. Developing limits for driving under cannabis. Addiction. 2007;102(12): 1910-1917. DOI: https://doi.org/10.1111/j.1360-0443.2007.02009.x.

10. Ramaekers JG, Robbe HWJ, O'Hanlon JF. Marijuana, alcohol and actual driving performance. Human Psychopharmacology: Clinical and Experimental.
2000;15(7): 551-558. DOI: https://doi.org/10.1002/10991077(200010)15:7<551::AID-HUP236>3.0.CO;2-P.

11. Rogeberg O, Elvik R. The effects of cannabis intoxication on motor vehicle collision revisited and revised. Addiction. 2016;111(8): 1348-1359. DOI: https://doi.org/10.1111/ add. 13347.

12. Fraser S, Bilsker D, Van K, Macpherson D, Capler R, Pelt V, et al. CANNABIS USE AND DRIVING: Evidence Review Canadian Drug Policy Coalition (CDPC). 2017 https://drugpolicy.ca/wp-content/uploads/2017/02/CDPC_Cannabisand-Driving_Evidence-Review_FINALV2_March27-2017. pdf [Erişim Tarihi: 11 Eylül 2018]

13. Schulze H, Schumacher M, Urmeew R, Auerbach K, Alvarez J, Bernhoft I. Driving under the Influence of Drugs, Alcohol and Medicines in Europe - Findings from the Druid Project. 2012.

14. Liu C, Huang Y, Pressley JC. Restraint use and risky driving behaviors across drug types and drug and alcohol combinations for drivers involved in a fatal motor vehicle collision on U.S. roadways. Injury epidemiology. Springer; 2016;3(1): 9. DOI: https://doi.org/10.1186/s40621-016-0074-7.

15. Verstraete A, Legrand S. Drug Use, Impaired Driving and Traffic Accidents.. European M. Spain; 2014.

16. Longo MC, Hunter CE, Lokan RJ, White JM, White MA. The prevalence of alcohol, cannabinoids, benzodiazepines and stimulants amongst injured drivers and their role in driver culpability: part ii: the relationship between drug prevalence and drug concentration, and driver culpability. Accident; analysis and prevention. 2000;32(5): 623-632. http://www.ncbi.nlm.nih.gov/pubmed/10908134.

17. Johnson MB, Kelley-Baker T, Voas RB, Lacey JH. The prevalence of cannabis-involved driving in California. Drug and Alcohol Dependence. 2012;123(1-3): 105-109. DOI: https://doi.org/10.1016/j.drugalcdep.2011.10.023

18. Sanal Y. Uzun Yol Araç Sürücülerinde Madde Kullanımı, Maddeye Erişebilirlik Ve Madde Testlerine Bakış Açısı. İstanbul Üniversitesi; 2009.

19. Kesen J, Topbaş M, Gündüz K, Yandı M. KTÜ Tıp Fakültesi Farabi Hastanesi Acil Tip Anabilim Dalına Trafik Kazas1 Sonucu Başvuran Sürücülerin Alkol Düzeyleri. Türkiye Acil T1p Dergisi. 2004;4(2): 51-54.

20. İdiz N, Karakuş A, Dalgıç M, Meseri R, Akgür SA. The Alcohol Levels in Fatal \&amp; Nonfatal Traffic Accidents in İzmir. Türkiye Klinikleri Adli Tıp ve Adli Bilimler Dergisi.] Turkiye Klinikleri; 2011;8(1): 6-11. http://www.turkiyeklinikleri.com/article/tr-the-alcohol-levels-in-fatal-nonfataltraffic-accidents-in-izmir-60327.html.

21. Acar F, Asirdizer M, Aker RG, Kucukibrahimoglu EE, Ates I, Erol Y, et al. A review of suspected cases of driving under the influence of drugs (DUID) involved in traffic accidents in Istanbul (Turkey). Journal of Forensic and Legal Medicine. 2013;20(6): 626-631. DOI: https://doi.org/10.1016/j. jflm.2013.03.028.

22. Erim B, Yumru M, Sercan M, Özen M, Abatan E. Psikiyatrik Hastalık ve Tedaviler Sürücülük Becerisini Etkiler mi? Klinik Psikiyatri. 2015;18: 82-89. 
23. Uysal MA, Kadakal F, Karşidağ C, Bayram NG, Uysal O, Yilmaz V. Fagerstrom test for nicotine dependence: reliability in a Turkish sample and factor analysis. Tuberkuloz ve toraks. 2004;52(2): 115-121. http://www.ncbi.nlm.nih.gov/ pubmed/15241694.

24. Turan M, Çilli A, Aşkın R, Herken H, Telcioğlu M, Kucur R. Cage Testi ile Alkol Kullanımı Üzerine Epidemiyolojik Bir Çalışma. Klinik Psikiyatri. 1999;2(4): 217-221. https:// www.journalagent.com/z4/vi.asp?pdir=kpd\&plng=tur\&un $=$ KPD-92582

25. Lajunen T, Özkan T. Kültür, Güvenlik Kültürü, Türkiye ve Avrupa'da Trafik Güvenliği, Tubitak Proje No: SBB-3023. 2004.

26. Sungur İ, Akdur R, Piyal B. Türkiye'deki Trafik Kazalar1nın Analizi. Ankara Medical Journal. 2014;14(3): 114-124.

27. Asbridge M, Poulin C, Donato A. Motor vehicle collision risk and driving under the influence of cannabis: Evidence from adolescents in Atlantic Canada. Accident Analysis \& Prevention. 2005;37(6): 1025-1034. doi: https://doi. org/10.1016/j.aap.2005.05.006.

28. Kaya N. Servis Şoförlerinin Trafikteki Tutum Ve Davranışları İle Psikolojik Durumlarının Trafik Kazaları Üzerine Etkisinin İncelenmesi. Gazi Üniversitesi; 2008.

29. Türkiye İlaç ve Tıbbi Cihaz Kurumu. Gripin kullanma talimatı. https://www.titck.gov.tr/PortalAdmin/Uploads/ KubKT/VwAMiixgFgLQVJ.pdf

30. Yildirim RC. Caffeine consumption in drivers of heavy vehicles in Turkey. Public Health. W.B. Saunders;
2003;117(5): 329-332. doi: https://doi.org/10.1016/S00333506(03)00076-3.

31. EWDTS - The European Workplace Drug Testing Society. http://www.ewdts.org/ewdts-guidelines.html.

32. Albrecht M. The 'Driving under the Influence of Drugs, Alcohol and Medicines' (DRUID) project of the European Commission. DMW - Deutsche Medizinische Wochenschrift. 2008;133(S 02): S45-S46. doi: https://doi. org/10.1055/s-2008-1081073.

33. Bernosky - Smith K, Aston E, Liguori A. Rapid drinking is associated with increases in driving-related risk-taking. Hum Psychopharmacol. 2012;27: 622-625.

34. Lenné MG, Dietze PM, Triggs TJ, Walmsley S, Murphy B, Redman JR. The effects of cannabis and alcohol on simulated arterial driving: Influences of driving experience and task demand. Accident Analysis \& Prevention. 2010;42(3): 859-866. doi: https://doi.org/10.1016/j. aap.2009.04.021.

35. Calafat A, Blay N, Juan M, Adrover D, Bellis MA, Hughes K, et al. Traffic Risk Behaviors at Nightlife: Drinking, Taking Drugs, Driving, and Use of Public Transport by Young People. Traffic Injury Prevention. 2009;10(2): 162-169. doi: https://doi.org/10.1080/15389580802597054.

36. Dağlığlu N. Kannabis ve Trafik (Kannabis Kullanımının Sürüş Yeteneğine Etkisi). Turkiye Klinikleri Journal of Pharmacology Special Topics. 2018;6(1): 62-67 